\title{
Construction Evaluation of Three Outperformance Options
}

\author{
Zibo Wang \\ School of Finance, Shanghai University, Shanghai, China \\ wzb0608@shu.edu.cn
}

\begin{abstract}
Locking the most promising company in a certain industry at an early stage is appealing for all investors, especially when the industry's capacity and prospect can be confirmed. The article tries to create three different special options to help investors to achieve this goal. Specifically, the construction process is based on outperformance options, Black-Scholes model, and some special valuation methods. According to the calculation, the price and the power of each future options are demonstrated clearly. Investors can choose one of them to satisfy their requirement for investment return and preference for risk. Four factors related to the price of the future options are also assessed based on sensitive analysis, i.e., one can understand the internal structure of the future options clearly. However, the research is based on the hypothesis that only 2 companies exist in the industry and people can determine the future of the industry. Therefore, following research can focus on multi-companies' industry and add more uncertain elements to make the results and process more general. These results shed light on eliminating the uncertainty of intra-industry competition, locking the industry leader early and increasing the investment return.
\end{abstract}

Keywords: Outperformance Option; Black-Scholes Model; Options Pricing.

\section{Introduction}

In finance, derivatives are the instruments whose price depends on the value of another asset. In particular, the stock option is a derivative whose price depends on the underlying stock price. Derivatives have also been used for many other assets--including, but not limited to, commodities (e.g., cattle, lumber, and copper), Treasury bonds, and currencies [1].

Option is one kind of derivatives that can help investors lock the delivery price in spot time and reduce the risk of the uncertainty of the market. The first options were used in ancient Greece to speculate on the olive harvest; however, modern option contracts commonly refer to equities. As for stock option, the contract of it gives the holder the right to buy or sell a set number of shares for a pre-determined price over a defined time frame. Options appear to have made their debut in what were described as "bucket shops". The bucket shop in 1920s America was made famous by a man named Jesse Livermore. In the beginning, the commodity futures markets and stock options markets were plagued with rampant illegal activities. Today, options are most widely traded on the Chicago Board of Options Exchange (CBOE) [2].

The paper focus on creating new options to break the limits of the present options. In some special market, some risk can be determined by researching the policy. In order to increase the efficiency of the option and decrease the price of it, new options can give people opportunities to take these risks, lower the cost, and lock other uncertainties. Present options are not able to clarify detailed types of risks and consider all of them in the pricing process. This will make the process complicated and unnecessary in some special situations.

The research chooses two companies from the photovoltaic industry in Shanghai securities composite index and picks the closing price of the right after recovery from last three years. The companies chose are in the same level and the industry is promising. One can determine the future market capacity of this industry After calculating the price of the future options based on these two companies' data, outcomes about the features of them can be obtained. As multi-asset options, researchers have designed and created some special ones. Rainbow Options, which means an option with more than one strike price on more than one underlying asset [3]. They are usually assigned a maturity time and a return equal to the maximum real-value portion of all the strike prices. The mapping function of rainbow options is given in follow: 
where $\Phi_{1}$ means it is a Call options or Put options, and it can be the Call options to asset 1 and the Put options to asset2. Basket Options, which means the weighted sum of two or more assets [4]. They usually have a strike price based on the sum of net weights. The payoff is related to the value of the portfolio assets, which are usually stocks, stock indices and currencies.

$$
\mathrm{M}_{1}=\sum_{i=1}^{m} F_{\mathrm{I}} \text { and } \mathrm{M}_{2}=\sum_{i=1}^{n} \sum_{j=1}^{n} F_{i} F_{j} e^{\rho_{i j} \sigma i \sigma j T}
$$

In this formula, $\mathrm{n}$ is the number of assets; $\mathrm{T}$ is the maturity time; $F_{i}$ and $\sigma_{i}$ are the forward prices and volatility of asset $\mathrm{I}, \rho_{i j}$ is the correlation between asset I and asset j. Government's policy instruction plays an important role in capital market in China, i.e., it's not a difficult thing to choose a promising industry in long term. In order to avoid the risk of companies' competition inside the industry, it is necessary to use a financial derivative instrument to lock the leader company in the early stages of a new industry. However, the degree to which people are favor or hate for risk and the confidence people have to their judgement for the industry's future development are different. Therefore, it is reasonable to construct three different options to match various people's needs and personalities. The results show clearly about the difference of the price of each options matching their different range of power and investigates the sensitivity of the price to four factors, including volatility, correlation, spot price and strike price.

The rest part of the paper is organized as follow. The Sec. 2 will introduce the data and the methods used to calculate the price of the options. The Sec. 3 will present the results of three options price separately and discuss their characteristics and limitations based on the results. The Sec.4 will test the level of sensitivity of the three options to the four factors mentioned before respectively, show them in a 3-D graph, and discuss the reasons behind it, which can help people understand the meaning of the options better. The Sec.5 will make the conclusions, propose the insufficiency of the research and give some directions for the future study.

\section{Data \& Methods}

All data is downloaded from Eastmoney website [5]. The basic data is the 3 years' closing stock price and they are chosen by monthly intervals after reinstatement. Risk free rate monthly $(0.13 \%)$ in China is also picked from this website. The stocks are named ZhongHuan Stock Price and TongWei Stock Price, and the price of them are shown in the Fig 1.
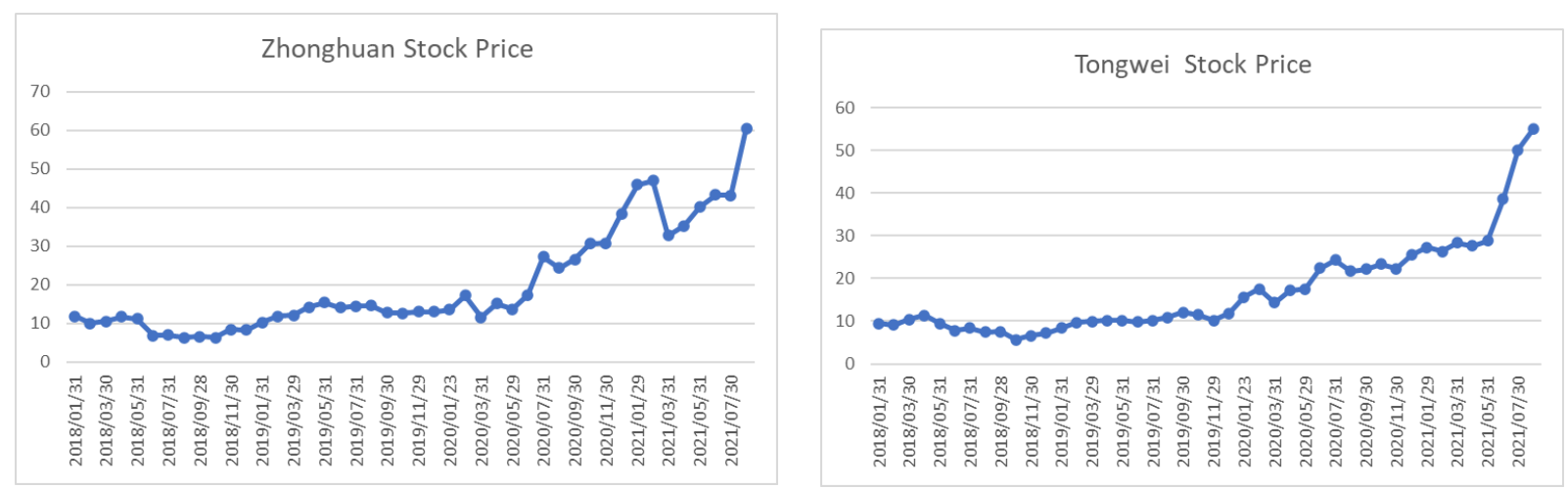

Fig 1. Stock Price of the two selected companies

The price of the options is calculated by the B-S models

$$
S_{T}=S_{0} e^{\left(\alpha-\frac{1}{2} \sigma^{2}\right) T+z \sigma \sqrt{T}}
$$


Based on Microsoft Excel. On October 10, 1997, the 29th Nobel Prize in economics was awarded to two American scholars, Robert Merton, a professor at Harvard Business School, and Myron Scholes, a professor at Stanford University. The Black Scholes option pricing model they founded and developed laid a foundation for the reasonable pricing of various derivative financial instruments priced by market price changes in emerging derivative financial markets, including stocks, bonds, currencies and commodities [6]. The reason why choose B-S model is that B-S model is more appropriate to Chinese warrants market, and the warrant is seriously overpriced in China. There is a strong manipulation in the market [7]. The paper aims at constructing the outperformance options. The outperformance option measures the outperformance, whether it be on the upside or downside, of one stock against another and pays this difference. Obviously, an outperformance option can also be structured between two different assets, like a stock and the oil price, in which case it measures the outperformance of the stock against the oil price [8]. With the help of Excel, two stocks' returns can be obtained, returns' standard deviation and correlation easily.

$$
\mathrm{Z}_{1}=\operatorname{normsinv}(\operatorname{rand}()) \text { and } \mathrm{Z}_{2}=\rho \mathrm{Z}_{1}+\operatorname{norm} \operatorname{sinv}(\operatorname{rand}()) * \sqrt{1-\rho^{2}}
$$

The formula are used to generate 2 series of 1000 random numbers and $\rho$ builds a relationship between them. Based on the formula, one can calculate the possible price in the end of the period in each situation (existing 1000 situations). According to the structure of each created options, the possible return in the end of the period can be calculated. Then, one derives the average number of these 1000 kinds of returns, which can be regarded as the options price in the end of the time period. Finally, the real options' price can be obtained by discounting the price to the current period with risk-free rate $(0.13 \%)$ and time maturity (1 year).

The first options named CALL-O Options. The formula of it is that

$$
\mathrm{C}_{\mathrm{T}}=\mathrm{MAX}\left(\mathrm{ST}_{1}-\mathrm{X}_{1}, \mathrm{ST}_{2}-\mathrm{X}_{2}, 0\right)
$$

According to this formula, one notices that someone who buy it have the power to choose the best performing stocks to delivery or give up to buy any stock. Therefore, with the help of the excel, the MAX () formula can be applied to get the return of each situation, then doing the same thing mentioned before to get the options' price.

The second options named CALL-O* Options. The formula of this options is that

$$
\mathrm{C}_{\mathrm{T}}=\mathrm{MAX}\left(\mathrm{ST}_{1}-\mathrm{X}_{1}, \mathrm{ST}_{2}-\mathrm{X}_{2}\right)
$$

On this basis, one can obtain the information that someone who buy it have the same power of the people who buy Call-O Options except that they cannot choose to give up delivery. Additionally, using Excel tools, the options' price can be obtained immediately.

The third options named CALL1+2 Options. Known from the name, this option is equal to buy two Call Options of two stocks at the same time. Therefore, the formula of it can be shown that

$$
\mathrm{C}_{\mathrm{T}}{ }^{\prime}=\mathrm{MAX}\left(\mathrm{ST}_{1}+\mathrm{ST}_{2}-\mathrm{X}_{1}-\mathrm{X}_{2}, \mathrm{ST}_{1}-\mathrm{X}_{1}, \mathrm{ST}_{2}-\mathrm{X}_{2}, 0\right)
$$

From the formula, it can be seen that someone who buy it can not only have the same power of the people who buy CALL-O Options, but also have the power to buy both stocks with the strike price. With the same function, its price can be derived easily.

After completing the pricing process, attention should be paid to research the sensitivity of the price to the four factors by using Excel as the main tool. As for the volatility, firstly, one of the two stocks' $\sigma$ is changed and is fixed the other one, then observing how the price will response to it. Secondly, two $\sigma$ are changed at the same time and observe the price's response. With regard to the correlation, spot price and strike price, similar functions are used. 


\section{Results \& Discussion}

\subsection{Call-O Options}

Call-O Options' price is lower than Call1+2, but higher than Call-O*, which is same to the expectation. The reason is that the power for people who buy this option is medium among these three special options. In our hypothesis, there are only two companies in the industry. Thus, the people who buy this option can lock the leader company (perform best in future) at the beginning of the period. Beside this power, they can also have the choice to give up buying any of the stocks in the end of the period, i.e., if the industry does not develop as their expectation, their max loss is zero (not considering the future fees). Nevertheless, they do not have the power to buy both stocks with strike price. On account of these features, people who buy the Call-O Options should not have to own an absolute faith that the industry will develop well, but are confident that the industry will divide extremely and the leading effect will be apparent.

\subsection{Call-O* Options}

Call-O* Options price is the lowest among these three options, which meets the expectation. The reason why it is the cheapest one is that its power range is the most limited among them. Though the formula is like the Call-O Options, Call-O* options cannot choose not to delivery. Therefore, people who buy this option must undertake more risk than the others. If the situation is extremely bad and stocks' price becomes horribly low, the investors who buy this option will experience huge losses. Besides this characteristic, the Call-O* Options is totally same to the Call-O Options. Due to these features, the price of Call-O* is lower than the price of Call-O. People who choose this option have the most confidence that the industry will have a bright future and there are no Black Swan in the following days. In this case, it is meaningless for them to pay more money for eliminating the risk of industry's decline.

\subsection{Call 1+2 Options}

Call1+2 Options is same to the sum of CALL Options1 plus CALL Options 2. The price of the Call1+2 is the highest among these three options, which also is in line with the forecast. There is no doubt that Call1 +2 has the largest range of power. Someone who buys it not only own all power of people who buy Call-O Options, but also can delivery both stocks with strike price. Therefore, the most losses when owning Call1+2 is same to owning Call-O, but owning Call1+2, people have the possibility to benefit more than buying Call-O options. Thanks to these features, the price of Call1 2 is the highest among them and same to buy Call Opitons 1 plus Call Options 2. People who decide to buy Call $1+2$ Options should not have to consider much about the development of industry in future and not need to worry about whether the industry will divide extremely in future, because they can own all bonus from the development of the industry and the companies without considering any risks. The only defect of Call1+2 Options is its high price. It can lower the investors expected returns without doubt.

Table 1. The Option price for the four types

\begin{tabular}{|c|c|}
\hline CALL-O & 19.8421 \\
\hline CALL-O* & 12.9455 \\
\hline CALL1+2 & 24.3754 \\
\hline call-1+call-2 & 24.3754 \\
\hline
\end{tabular}

\subsection{Limitation}

In the process of calculation, the options fee is not considered. Two series of 1000 random numbers are fixed in order to calculate the price conveniently. Infinite random situation cannot be listed in the contemporary calculators to eliminate any occasionality. A hypothesis is made that only two companies in the industry, however it is almost impossible in real life, so the pricing process is not 
practical to be used in the normal options pricing directly. The pricing process is based on the history data and not consider the future market, industry and company risk factors, i.e., the price is not exercise and perfect.

\section{Sensitive Teste}

\subsection{Volatility}

There is evidence that unexpected stock market returns are negatively related to the unexpected change in the volatility of stock returns [9]. The impact of futures trading on the volatility of the underlying spot market is intensely debated. One viewpoint suggests that speculative trades in futures markets tend to stabilize or even reduce volatility of the underlying spot market. On the other hand, some researchers have found that excessive speculation in futures markets destabilizes and increases volatility of the spot market [10]. Due to the construction of the options, it is necessary to test the sensitivity of the price to the volatility. Two steps verification approaches are implemented. The first step is to fix the volatility of one stock and change the other ones', then seeing how the price of three options response to this change. The second step is to change both stocks' volatility at the same time, and see how the response of the price.

According to the first step's result, with the increase of the volatility, all three options' price will rise in a linear trend. Moreover, their slopes are closed to each other. As illustrated in Fig. 2 there is no apparent relationship should be noticed among these three lines. The influence of the volatility on the price is obvious and the difference of the level of the influence on each stock is not so obvious, so it is not necessary to pay more attention on this little difference.

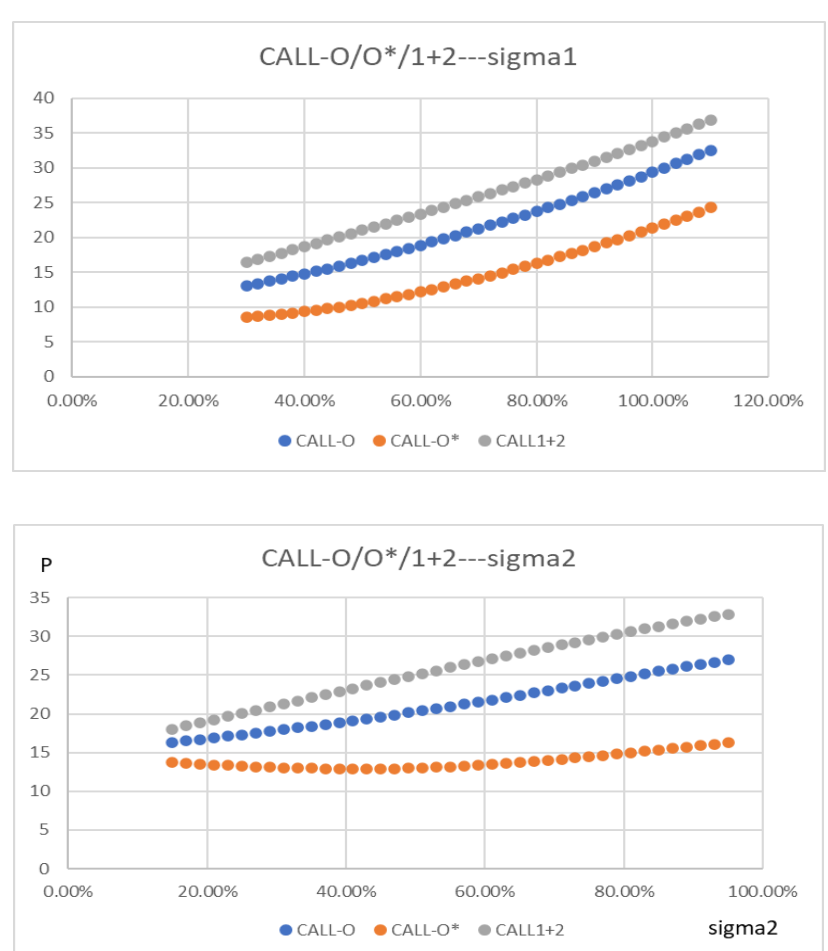

Fig 2. Sensitivity of Volatility Test for fixing one sigma while changing the other.

According to the second steps' result, the Fig. 3 shows that when two volatilities of the stocks change together, the price change more fiercely. In the graphs of Call-O and CALL-O*, it is clear that with the increase of both volatilities, the price rise in a little exponential form, rather than a liner one. However, in the subplot of Call1+2, the price still exhibits a linear growth, instead of the exponential one's. Therefore, because of the fact that the Call1+2 is just constructed by the sum of two options, the combination of the both change of the volatility has no special effect on the price of 
options. It just like price change because of A plus price change because of B. This relationship is totally linear form. However, the structure of the CALL-O and CALL-O* have a relationship like that either A or B. Hence, the change of both volatilities has an additional effect on the price of the options, which will catalyze the growth of the price and create an exponential trend.

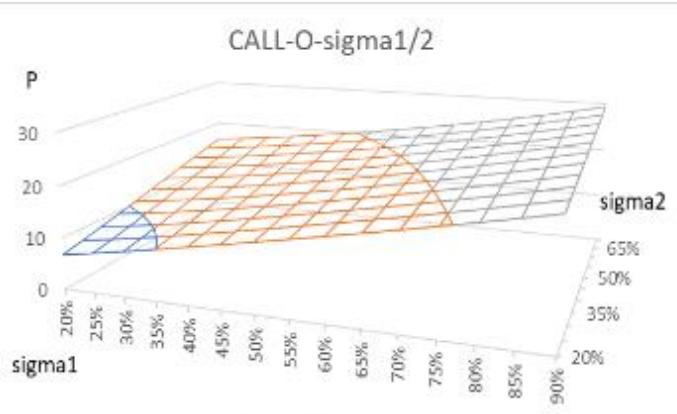

$\square 0-10 \square 10-20 \square 20-30$


Fig 3. Sensitivity of Volatility Test for varying two sigma simultaneously

\subsection{Correlation}

With the same function, the correlations between stocks (the two sets random numbers) are tuned and the responses of the price of three options to it are observed accordingly. As displayed in Fig. 4, it is clear that when the correlation rise, the price of the Call-O and Call-O* will decrease, however, the price of the Call1+2 has not been affected. The slope of the Call-O* Options is fiercer than the slope of the Call-O Options, which demonstrates that the influence of the correlation on the price of the Call-O* is bigger than it on the price of the Call-O. This result can be explained by the fact that due to the lack of the power to give up cancelling the delivery, Call-O* Options' structure contains a closer relationship between two stocks and when the correlation changes, this closer relationship enables the price of it respond more largely. As to the Call1+2, the correlation has no effect on its price because during the pricing process, the price is only the sum of the price of two options. Without the intervention of the either A or B relation, correlation is not a factor deciding the price of Call $1+2$.

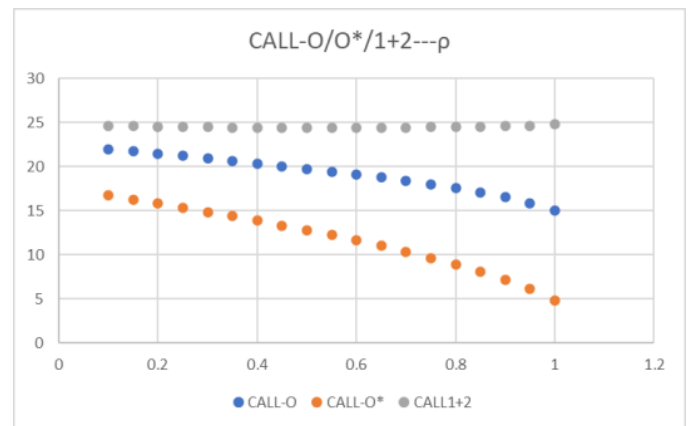

Fig 4. Sensitivity of Correlation Test 

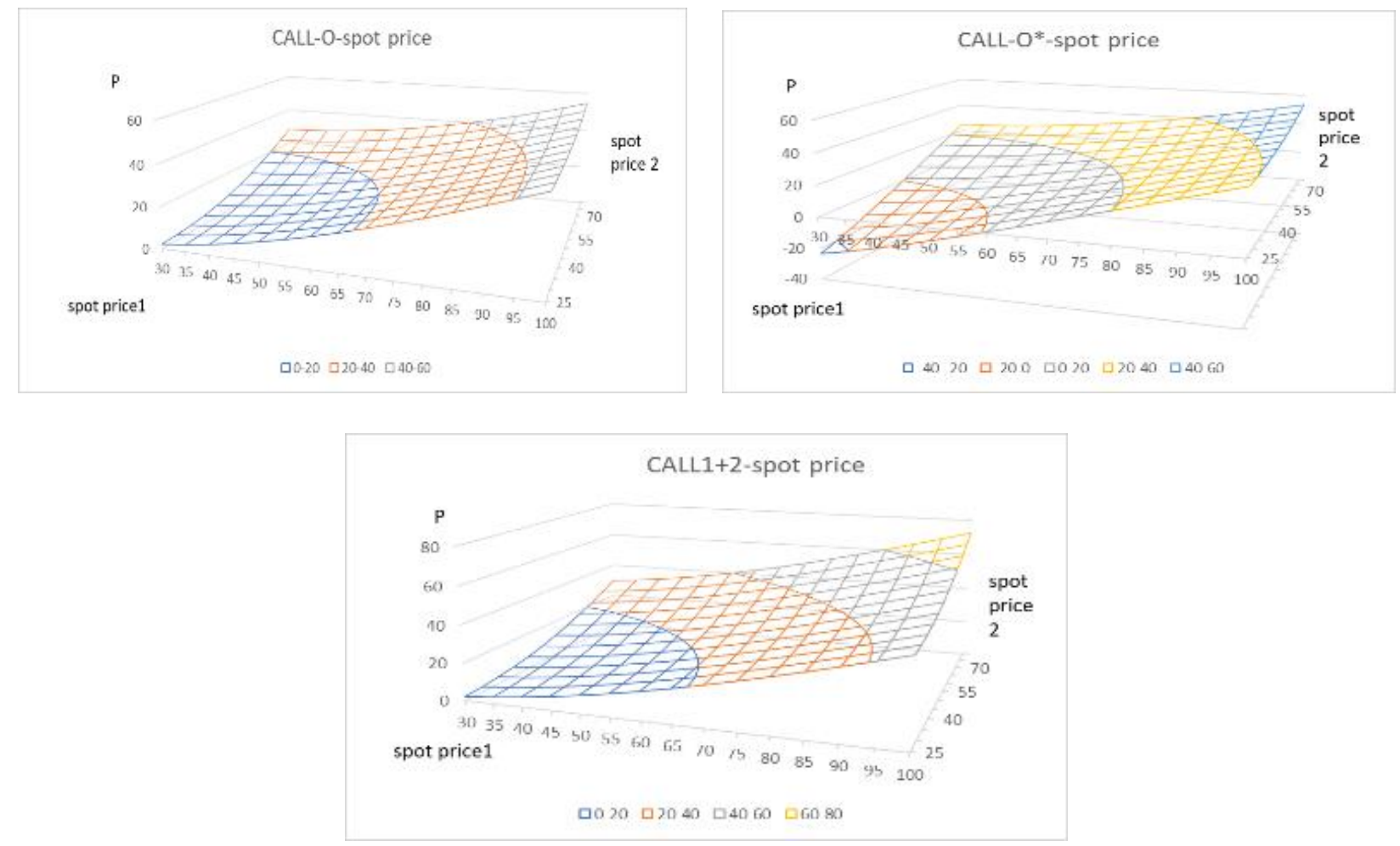

Fig 5. Sensitivity of spot Price Test

\subsection{Spot Price}

As depicted in Fig. 5, all price of three options has an exponential rise as the increase of the both spot price of two stocks. The level of the response, in other words, the range of the price's change, is that price of Call-O* is similar to the price of Call-O and both of them is lower than the price of Call1+2. Additionally, the price of the Call-O* can be negative when the spot price is extremely low. This result meets the expectation because when the spot price is low enough, people who buy it have a huge possibility to experience a loss. Therefore, the price of this options can be negative. The spot price has a higher effect on Call1+2 options because that when spot price change, it can affect the price of two stocks separately, and the whole influence is the sum of the effect on A stock and the effect on B stock. Nevertheless, there is some overlap area between the effect of spot price on A stock and the effect of it on B stock, i.e., the effect should be the sum of two effect minuses the overlap area. In this way, it is reasonable that the price change of Call-O and Call-O* is gentler than the change of Call1+2.

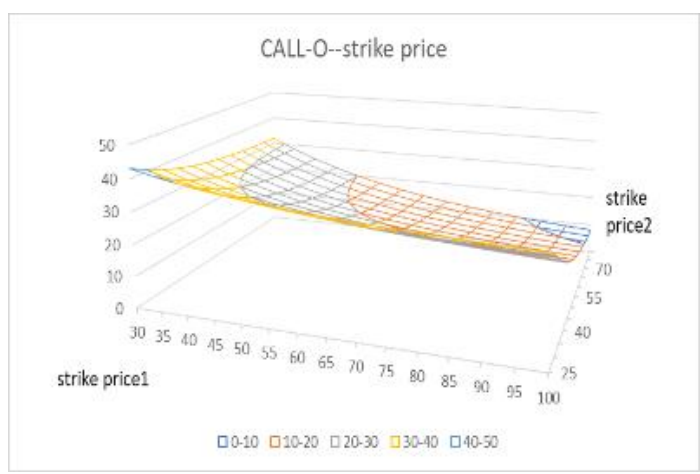

(a)



(b) 


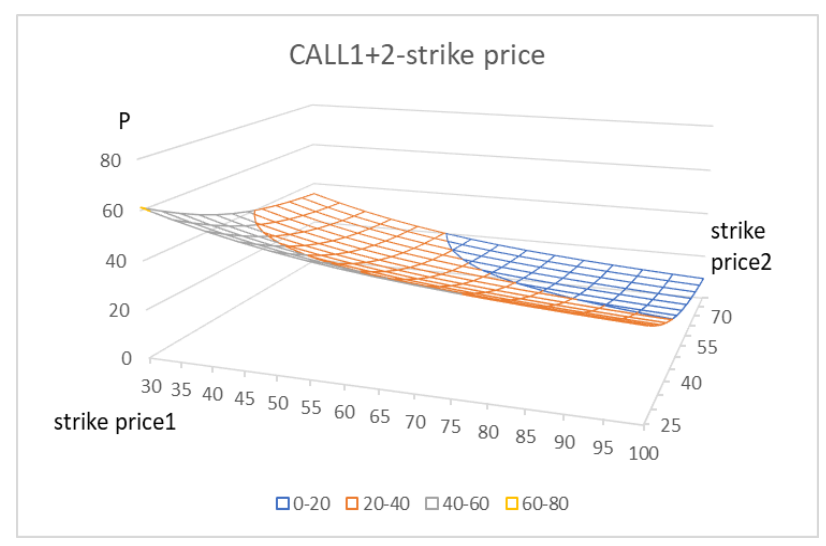

(c)

Fig 6. Sensitivity of strike Price Test

\subsection{Strike Price}

The researching function and the result is similar to them in the part of Spot price (as illustrated in Fig. 6), but the graph and the consequence are reversed to the them. In additions, one can notice that when the strike price is high enough, it is possible that the price of the Call-O* options is negative, because when the strike price is high enough, it is largely possible for investors to lose their money. Call1+2 options still have the widest range of changing section responding to the change of strike price, the reason for that is same to the reason explained in the Spot price part.

\subsection{Limitation}

The range of change of volatility, correlation, spot price and strike price are limited. The article does not demonstrate the deep relationship between the volatility and the options' price and the difference between changing $\sigma_{1}$ and fix $\sigma_{2}$ and changing $\sigma_{2}$ and fix $\sigma_{1}$. The article shows no reason about why the line of Call-O* in fixed $\sigma_{1}$ graph is gentler than the line in fixed $\sigma_{2}$ graph. The article does not research the deep relationship between the correlation and the price of three options and how the correlation determines the price of Call-O and Call-O* Options. Similarly, the article pays no attention to find how the spot price and the strike price can determine the price of the three options in detail.

\section{Conclusion}

In summary, this paper constructs three special options and evaluates the performances accordingly to help investors to lock the leader company in the early stage of the development of the industry, reduce risk of companies' competition and increase the returns of them. Specifically, the constructed three options are priced based on the B-S model, which show outperformance options' idea with the help of Excel. The result is visual, direct and obvious and the reason behind it can be find from the visualized graph with some efforts. The pricing process and the results can only be established in the hypothetical model, which is not exist in the real life. Researchers can add more uncertain factors mentioned in the paper to complicate the model and make it closer to normal situation, thus creating the model which can really be used in the investment. The paper contributes to find a new train of thought to create financial derivative instrument to help investor to ease the risk of competition between the companies inside a common industry.

\section{Conflict of Interest}

The authors declare no conflict of interest. 


\section{References}

[1] Option pricing[J]. Quantitative Finance for Physicists, 2005:93-109.

[2] Investopedia. The History of Options Contracts [EB/OL]. [2021/10/1]. https:// www. Investopedia. com/ articles/ option investor/10/history-options-futures.asp.

[3] Hucki Z Kolokoltsov V N. PRICING OF RAINBOW OPTIONS: GAME THEORETIC APPROACH[J]. International Game Theory Review, 2007, 9(02).

[4] Ruggero, Caldana, Gianluca, et al. General closed-form basket option pricing bounds[J]. Quantitative Finance, 2015.

[5] Eastmoney. stock data [EB/OL]. [2021/10/2]. https://www.eastmoney.com/.

[6] wiki. Overview of B-S Option Pricing Model [EB/OL]. [2021/10/1]. https://wiki.mbalib.com/wiki/BlackScholes.

[7] Dai J. Warrants Pricing: The Classic B-S Model vs. CSR Model[J]. Chinese Journal of Management Science, 2009.

[8] Weert F D. Exotic Options Trading (Weert/Exotic) \| Outperformance Options[J]. 2012, 10.1002/ 9781 119208730:129-133.

[9] French K R, Schwert G W, Stambaugh R F. Expected Stock Returns and Volatility[J]. Journal of Financial Economics, 1987, 19(1):3-29.

[10] Antoniou A, Foster A J.THE EFFECT OF FUTURES TRADING ON SPOT PRICE VOLATILITY: EVIDENCE FOR BRENT CRUDE OIL USING GARCH[J]. Journal of Business Finance \& Accounting, 2010, 19(4):473-484. r. 